\title{
Ideal cardiovascular health at age 5-6 years and cardiometabolic outcomes in preadolescence
}

\author{
Hester Jaspers Faijer-Westerink', Mette Stavnsbo², Barbara A. Hutten ${ }^{3}$, Mai Chinapaw ${ }^{4}$ and Tanja G. M. Vrijkotte ${ }^{1^{*}}$ (D)
}

\begin{abstract}
Background: The American Heart Association (AHA) developed a definition of ideal cardiovascular health (ICH) based on the presence of both ideal health behaviours (diet, physical activity, weight status and smoking) and ideal health factors (glucose, total cholesterol and blood pressure levels). However, research of ICH in the paediatric population is scarce. We aimed to study $\mathrm{ICH}$ at age 5-6years by extending the original $\mathrm{ICH}$ score with the health behaviours: sleep duration, screen time and prenatal smoke exposure, and to evaluate its association with cardiometabolic outcomes at age 11-12.

Methods: A total of 1666 children aged 5-6years were selected from the database of the ABCD-study, a prospective cohort study on the health and development of children born in Amsterdam, the Netherlands. Of these, 846 (50.8\%) were boys and 1460 (87.6\%) had a healthy weight. Data on self-reported health behaviours and health factors were used to calculate the $\mathrm{ICH}$ scores (original and extended) by adding the frequency of scoring 'healthy' on each indicator, based on international cut-offs. The children were followed up for 6 years and cardiometabolic outcomes (carotid intima-media thickness (CIMT), blood pressure, glucose and lipids) were measured. Associations between ICH (both original and extended) and cardiometabolic outcomes were examined using multivariable regression models.
\end{abstract}

Results: At age 5-6years, 11\% scored poor (score 1-5), 56\% intermediate (score 6-7) and 33\% good (score 8-9) on extended ICH. Healthy diet and normal total cholesterol concentrations were the least prevalent. Neither the original nor the extended ICH scores were associated with CIMT at age 11-12. A higher score on the extended ICH was associated with lower total cholesterol ( $p$ for trend $<0.001$ ), lower systolic ( $p$ for trend $=0.012$ ) and diastolic blood pressure ( $p$ for trend $=0.011$ ), and lower body mass index $(\mathrm{BMI})(p<0.001)$ at age $11-12$. The original ICH score was associated with lower total cholesterol $(p<0.001)$ and BMI $(p<0.001)$ only.

Conclusion: Our findings suggest that extending the $\mathrm{ICH}$ score in young children with additional health behaviours improves prediction of some cardiometabolic outcomes, but not CIMT in preadolescence, compared to the original $\mathrm{ICH}$ score. We would recommend other researchers to incorporate objective measures of health behaviours and longer follow-up to find out whether associations persist into adulthood.

Keywords: Children, Ideal cardiovascular health, Cardiovascular risk, Epidemiology, Health behaviours

\footnotetext{
* Correspondence: t.vrijkotte@amsterdamumc.nl

1 Department of Public and Occupational Health, Amsterdam Public Health Research Institute, Amsterdam UMC, University of Amsterdam, PO Box 22700, Meibergdreef 9, room J2-209, 1100 DE Amsterdam, The Netherlands

Full list of author information is available at the end of the article
} 


\section{Introduction}

Cardiovascular diseases (CVDs) are the leading cause of death and remain one of the most important health challenges worldwide [1]. Although most children are born with optimal cardiovascular health, clustering of CVDs (or cardiometabolic) risk factors already occurs in childhood [2]. As both health behaviours as well as cardiometabolic risk factors track from childhood into adulthood, maintaining cardiovascular health in children is an important step to take [3]. However, to develop successful strategies with special focus on cardiovascular health in children, the most important CVD risk factors in children need to be identified.

To define and measure cardiovascular health of individuals, the American Heart Association (AHA) created the construct of ideal cardiovascular health (ICH). The ICH construct consists of seven metrics: four health behaviours (not smoking, having a healthy weight status, being sufficiently physically active and eating a cardiovascular-healthy diet), and three health factors (healthy levels of total cholesterol, blood pressure and glucose) [4].

.The construct of ICH is already used in populationbased studies, especially focusing on adults. Reviews of these studies show that there is an inverse association between ideal $\mathrm{ICH}$ metrics and the incidence of CVDs [5-8]. There is also evidence that even one point higher on the ICH metrics, gives a reduction of $19 \%$ in cardiovascular related mortality [7]. Prevention strategies focusing on the factors included in the ICH metrics is thus highly recommended. However, studies on the prevalence of ICH in children are scarce [9-12]; only three have been conducted in children $>12$ years of age $[9,11,12]$. Further, few studies have investigated the relationship between ICH and cardiometabolic outcomes in populations under the age of 25 , but these studies mainly focus on individual components [13-18].

.The definition of ICH in children differs slightly from the adult definition [4]. Smoking is excluded in the ICH definition in children, as children younger than 12 years normally do not smoke. Also, recommended physical activity levels are higher for children: $\geq 60 \mathrm{~min}$ of moderate to vigorous physical activity per day.

Growing evidence shows that the health behaviours included in the ICH construct are not the only risk factors for CVD. In adults, excessive sedentary time and short sleep duration have i.e. shown to be risk factors too. The longitudinal evidence for health effects of sedentary behaviour is inconsistent, but the evidence for screen time alone is more convincing [19]. As health behaviours lead to changes in health factors, adding more components to the ICH construct could make the construct more sensitive for the prediction of cardiometabolic outcomes. Thus we propose an extended version of the $\mathrm{ICH}$ definition for the purpose of this study by adding screen time, sleep duration, and prenatal smoke exposure. All three components have been associated with cardiovascular health in children [20, 21].

.The aim of our study was to apply this extended $\mathrm{ICH}$ score to a cohort of 5-6 year old children and evaluate its association with cardiometabolic outcomes at age 11-12 years. As children aged 11-12 years old do not yet experience cardiovascular diseases, we focused on the carotid intima-media thickness (CIMT), a surrogate marker for CVD [22], as our primary outcome. We compared the results with the original ICH definition.

\section{Methods}

\section{Study population and design}

This study was part of the Amsterdam Born Children and their Development (ABCD)-study, a prospective cohort study based in the Netherlands. The ABCD-study aims to examine the associations between maternal lifestyle, health and psychosocial circumstances during pregnancy and the child's health at birth and later in life [23]. Between January 2003 and March 2004, 12,373 pregnant women were approached (>99\% of the target population) during their first prenatal visit to an obstetric care provider, of which 8266 agreed to participate and filled out a pregnancy questionnaire without getting any incentives.

Two weeks after their child's fifth birthday, mothers who gave permission for follow-up and whose addresses could be retrieved $(n=6161)$ received a questionnaire on the health, development and behaviour of their child and an invitation for the child's health check. The questionnaire was returned for 4488 children, of which 2041 participated in the health check consisting of among other, a finger prick for blood collection after an overnight fast, measurements of height, weight, waist circumference and measurements of blood pressure. After the health check children received a small gift. For those children who participated in the health check, mothers were also asked to fill in a validated food frequency questionnaire (FFQ) [24]. Information on all $\mathrm{ICH}$ components was available from 1666 children at age 5-6 years. A randomly selected subgroup of 1081 children were approached for participation in follow-up health measurements at age 11-12 years (March 2015 to June 2016). The health check was similar to the health check at the age of 5, but ultrasound measurements of CIMT were added. For participation children received a gift voucher worth of 10 euros. From this group, 607 children participated at both time points and 559 children had information on the cardiovascular profile. Information from these 559 children were used to investigate the association between ICH at age 5-6 and cardiovascular health at age 11-12. The information of 459 
children could be used for the association between ICH at age 5-6 and CIMT. Flowchart of the study population is presented in Fig. 1.

For inclusion in stage 1 of the current study the children had to meet the following criteria: 1) availability of information on maternal smoking status during pregnancy, 2) participating in the 5 year health check with cardiovascular measurements, 3) filled out FFQ, 4) filled out questionnaire on physical activity, sedentary behaviour and sleep duration. For inclusion in stage 2 of the study, children had to participate in the 11 year health check with cardiovascular measurements. Exclusion criteria's from participating in the study were: non-fasting blood samples, congenital heart malformations or use of medication altering blood pressure or lipid concentrations.

\section{Demographic information}

Ethnicity was based on the mother and her mother's country of birth, derived from the pregnancy questionnaire and categorized into Dutch, Turkey, Moroccan and Surinamese (the three most common non-Western ethnicities in the Netherlands). The remaining ethnicities were categorized into western and non-western ethnicities. Information on mother's and father's weight and height to calculate parent's body mass index (BMI) was

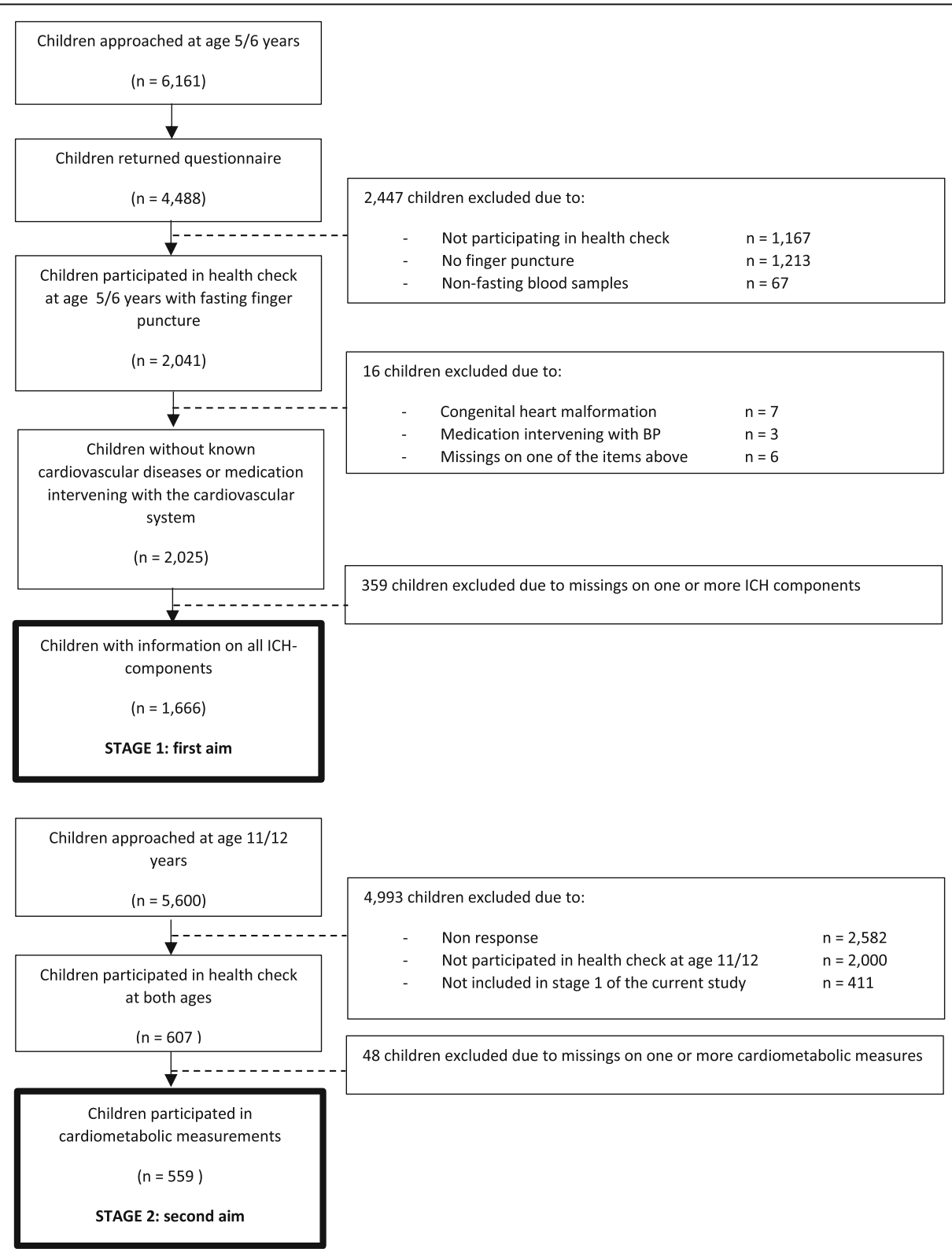

Fig. 1 Flowchart of study population, baseline in 2008-2010, follow-up in 2014-2015 
derived from the questionnaire mother's received after their child's fifth birthday. Information on socioeconomic status (maternal education level) and cardiovascular diseases in the immediate family was also derived from this questionnaire. Maternal educational level was divided into low (primary school, technical secondary education, lower vocational secondary education), moderate (degree higher vocational secondary education, academic secondary education, intermediate vocational education) or high (degree higher vocational education, university). Cardiovascular diseases in the immediate family were answered by marking 'no', 'yes' or 'don't know' for the following diseases by the mother, the child's biological father and their first degree relatives: overweight, hypertension $<55$ years, high cholesterol, stroke $<55$ years, heart attack $<55$ years and dead from heart attack $<55$ years [25]. Information on the child's sexual maturation at the age of 11-12 was assessed by the Tanner scale, scored by the mother [26].

\section{Health behaviours}

Considered health behaviours were weight status, physical activity, diet, screen time, sleep duration and prenatal smoke exposure, apart from weight status all reported by the mother. Weight and height were measured once to calculate BMI (weight in $\mathrm{kg} /$ height in $\mathrm{cm}^{2}$ ). Weight was measured to the nearest $100 \mathrm{~g}$ by using a Marsden weighing scale (model MS-4102, Oxfordshire, UK) and height to the nearest $\mathrm{mm}$ with a Leicester portable height measure (Seca, Hamburg, Germany). The health check was administered at both time points by trained student assistants, trained $\mathrm{PhD}$ candidates and research staff of the ABCD-study. At age 5-6 years the measurements took place at the child's primary school except for those children enrolled in small schools, children who moved outside Amsterdam and the 11-12-year-old children. For these children, the health check took place at a central location during the weekend and holidays. For defining metabolic syndrome, waist circumference was measured placing a Seca measuring tape around the abdomen between the costal border and iliac crest. Children aged 5-6 wore underwear only, children at age 11-12 wore sport outfits. Information on physical activity included both recreational and organized physical activity outside school hours as well as transport to and from school cycling. Hours of recreational physical activity was assessed by asking the hours of playing outside at schooldays and in weekends for both summer and winter. The total hours of organized sport activities per week and the total hours of cycling to and from school were added to a total physical activity score [27].
.The FFQ that was used to evaluate the children's food consumption consisted of questions regarding the 71 most consumed food items by Dutch children [23]. For the present study, we included information regarding fruits and vegetable intake, fish intake, fibre intake and intake of sugar-sweetened beverages in line with the healthy diet definition of the AHA [4]. The AHA guideline looks at the intake of fibre-rich whole grains, while the FFQ used in this present study measures total intake. Fibre intake was considered sufficient if it accounted 3 $\mathrm{g} / \mathrm{MJ}$, recommended by the Health council of the Netherlands [28]. Sodium intake could not be assessed with our FFQ. For other components besides fibre and sodium, the AHA cut-offs for a healthy diet were used: $\geq 450 \mathrm{~g}$ of fruits and vegetables/day, $\geq 2$ servings of fish/ week with a total weight of $\geq 200 \mathrm{~g}$ and $\leq 450 \mathrm{kcal}$ of sugar-sweetened beverages/week based on a $2000 \mathrm{kcal}$ diet. A comparison of our definition with the AHA definition can be found in Supplementary Table 2.

For the assessment of screen time, the number of hours per day children were watching TV, DVD or VIDEO and how many hours they played games on computer, $\mathrm{XBOX}$ or other types of videogames were asked. Hours of screen time for both schooldays and weekends were ranked in six categories from '(almost) never' to 'five or more hours per day' [29]. Information on children's sleep duration included the total hours of sleep per day, separately for schooldays and in the weekends. The average hours of sleep per day was calculated by multiplying the hours of sleep on schooldays by five and the hours of sleep in the weekend by two and then adding these two numbers together, divided by seven. For all the above stated behaviours, a weighted weekly average was calculated. Mother's smoking habits during pregnancy were assessed from the pregnancyquestionnaire in which mothers scored the number of cigarettes smoked daily.

\section{Health factors}

At age 5-6, plasma glucose, serum lipids and triglyceride concentrations were determined in capillary blood, collected after an overnight fast by a finger puncture by using a validated kit, developed for ambulatory purposes (Demecal: LabAnywhere, Haarlem, The Netherlands) [30]. At age 11-12, capillary blood was collected by finger puncture after $3 \mathrm{~h}$ fasting and analysed by the pointof-care analyser Alere Cholestech LDX machine using Lipid Profile and GLU cassettes (Cholestech Alere Health Hayward, CA, USA) [31]. At both time points, blood pressure was measured by the Omron 705 IT (Omron Health Inc., Bannockburn, IL, USA) [32] in sitting position with the arm supported at the heart level. After a test reading and $15 \mathrm{~min}$ of rest, blood pressure was measured twice on the upper right arm with an 
appropriate cuff. If these measurements differed $>10$ $\mathrm{mmHg}$, a third measurement was performed [33]. The systolic and diastolic blood pressure were determined by averaging the two closest measurement. The research location and research staff were similar to those reported by the calculation of weight and height.

\section{Defining $\mathrm{ICH}$ at age 5-6 years}

On each ICH component, children could score 'ideal' (score $=1$ ) or 'non-ideal' (score $=0)$. To define ICH components as ideal, the AHA recommendation was used for the following components: BMI $<85$ th percentile according to the WHO growth reference [34] ideal diet when three out of four components were met [4], fasting plasma glucose $<5.6 \mathrm{mmol} / \mathrm{L}$, total cholesterol $<4.40$ $\mathrm{mmol} / \mathrm{L}$ and blood pressure $<90$ th percentile based on reference values from the guideline of the American Academy of Pediatrics [35]. Physical activity was considered ideal according to the AHA when children were physically active at moderate or vigorous intensity for at least $60 \mathrm{~min}$ per day. In our study the children of mother's who reported a total physical activity score of $\geq 7 \mathrm{~h}$ per week were considered ideal [9].

.For the extended ICH score, a score on three additional health behaviours were added. There is no evidence-based cut-off for screen time. Based on a commonly used cut-off, we considered $\leq 2 \mathrm{~h}$ of screen time per day as ideal [29]. Sleep duration was considered ideal if children slept $\geq 10 \mathrm{~h}$ per night as recommended by the National Sleep Foundation [36]. Children from mothers who reported not having smoked during pregnancy received an ideal smoking score. The definition of each component according to AHA and the additions are listed in Supplementary Table 2.

The score on extended ICH ranged from zero to nine; zero to five points was considered poor, six and seven points intermediate and eight or nine points good $\mathrm{ICH}$. This subdivision was made to create roughly equal groups in size, to compare groups with relatively poor, intermediate and good cardiovascular health.

\section{Carotid intima-media thickness}

Ultrasound measurements of the common carotid artery (CCA) were performed with the automated Panasonic Cardio Health Station V1.8 (Diagnostic Ultrasound System GM-72P00A) by three experienced ultrasound technicians at the central locations where the health check took place. During this measurement, children were in lying position with their head at a 45 degree angle. CIMT was measured bilaterally at angles 150, 120 and 90 on the right CCA and at 210, 240 and 270 on the left CCA. The software automatically identified the region of interest and froze the image. Mean CIMT was calculated by averaging the measured angles, with a minimum of at least three angles. Out of 559 individuals, 459 individuals had a CIMT measurement with at least three angles, whereof 442 individuals had all six angles measured. Increased risk CIMT was defined as a CIMT of $\geq 90$ th percentile of the cohort.

\section{Cardiometabolic outcomes}

Secondary outcomes were glucose, total cholesterol, high-density lipoprotein cholesterol (HDL-C), triglycerides (TG), systolic and diastolic blood pressure and BMI at the age of 11-12 (all continuous). The following outcome variables were dichotomized: low HDL-C $(<10$ th percentile), high TG ( $\geq 75$ th percentile), (pre) hypertension (systolic and/or diastolic blood pressure $\geq 90$ th percentile) and overweight (BMI $\geq 85$ th percentile). Participants were considered having metabolic syndrome when they met three or more of the following criteria: waist circumference $\geq 75$ th percentile, (pre) hypertension, low HDL-C, high TG and glucose $\geq 75$ th percentile [37]. All percentiles in this paragraph are based on data of the own cohort.

\section{Statistical analyses}

We investigated the representativeness of the included subgroup by comparing the baseline characteristics between the non-included group (i.e. those who were approached at age 5-6, but did not participate in the questionnaire and/or health check at age 5-6) and the included group (i.e. those who participated both in the questionnaire and health check at age 5-6) by an independent samples $t$-test for continuous variables and the $\mathrm{X}^{2}$ test for categorical variables.

\section{Stage 1}

Differences in demographic characteristics between the poor, intermediate and good ICH groups (based on extended ICH score) were tested by one-way analysis of variance (ANOVA) for continuous variables and the $x^{2}$ test for the categorical variables. The association of individual health behaviours, health factors and lipids with the extended ICH score at age 5-6 was evaluated by means of sex- and age adjusted multivariable linear regression models. $P$-for-trend was calculated considering $\mathrm{ICH}$ as a continuous variable.

\section{Stage 2}

We studied the association between the extended $\mathrm{ICH}$ score at age 5-6 with CIMT and cardiometabolic outcomes at age 11-12 by means of multivariable linear regression models for continuous outcomes and multivariable logistic regression models for dichotomous outcomes. We considered the ICH variable as a continuous variable to calculate p-for-trend. For these analyses, all models included age, sex and maturation. To examine 
whether the association with respect to the dichotomous outcomes was present in children with a healthy weight at baseline, we repeated the logistic regression analysis excluding children with overweight at age 5-6.

All analyses were repeated with the original ICH score. IBM SPSS Statistic software version 20.0 (IBM Corp, Armonk, NY, USA) was used for the analysis. A $p$-value of $<0.05$ was considered statistically significant.

\section{Results}

\section{Comparison of included and non-included children of the} ABCD-cohort

Compared to those who were not included $(N=2822)$, the included children $(N=1666)$ were younger, had more often mothers with Dutch ethnicity and a higher educational level and reported more often family history of CVD. No differences were observed in parental weight status and boy-girl distribution. (Supplementary Table 1).

\section{Stage 1}

\section{Characteristics of the study subjects}

Mean age (standard deviation (SD)) of the children at baseline was $5.7(0.4)$ years. The prevalence of individual ideal ICH components were: normal glucose concentration (97.1\%), no prenatal smoke exposure (92.3\%), adequate physical activity (88.2\%), healthy weight status (87.6\%), normal blood pressure (86.9\%), sufficient sleeping hours $(81.4 \%)$, screen time $<2 \mathrm{~h}(80.4 \%)$, normal total cholesterol concentration (69.7\%) and healthy diet (2.0\%). According to the extended $\mathrm{ICH}$ the majority of children had either intermediate $(56 \%)$ or good $(33 \%)$ ICH, which means respectively 6-7 or 8-9 ideal components. Compared to children with poor ICH $(11 \%, 1-5$ ideal components), children with a good $\mathrm{ICH}$ were more likely to have a Western ethnicity, higher educated mothers, normal weight parents and less frequent have a family history of CVD, see Table 1.

Table 2 shows the results of the associations between extended ICH scores and cardiovascular health outcomes at age 5-6 years. Children with higher scores had lower levels of health factors and higher percentages of ideal health behaviours.

\section{Stage 2}

\section{Extended ICH score and carotid intima-media thickness}

The mean CIMT at age 11-12 years was $0.462 \mathrm{~mm}(\mathrm{SE}=$ 0.001). The association between extended ICH score at age 5-6 years and CIMT was not statistically significant ( $p$ for trend $=0.12$; Table 3 ). Further, no statistical significant association was observed between extended $\mathrm{ICH}$ and the dichotomous variable 'increased risk CIMT' (odds ratio (OR) [95\% confidence interval $(95 \% \mathrm{CI})$ ]: 1.04 [0.77-1.40], $p=0.80$ (Table 4).

Extended ICH score and cardiometabolic outcomes The extended ICH score at age 5-6 was significantly associated with total cholesterol ( $p$ for trend $<0.001$ ), systolic blood pressure ( $p$ for trend $=0.01$ ), diastolic blood pressure $(p$ for trend $=0.01)$ and BMI $(p$ for trend $<0.001)$ at age 11-12. No significant association was found for glucose ( $p$ for trend $=0.92)$, HDL-C $(p$ for trend $=0.31)$ and triglycerides ( $p$ for trend $=0.47$ ) (Table 3 ).

Table 4 shows OR $(95 \% \mathrm{CI})$ for the extended ICH score and the prediction of cardiometabolic outcomes at age 11-12 years, adjusted for age-, sex- and maturation. Extended ICH was inversely associated with overweight (OR [95\% CI]: 0.54 [0.43-0.68], $p<0.001$ ). When children with overweight at age 5-6 were excluded, the association of ICH at age 5-6 and overweight at age 1112 remained significant (OR: 0.66 [0.48-0.91], $p=0.01$ ). No significant association was found between extended ICH score and metabolic syndrome, (pre-)hypertension, low HDL-C and high triglycerides.

\section{Comparison between the extended and original ICH score} Overall the results were similar regardless of using the original or extended ICH score (Supplementary Table 3). However, the prospective results revealed no statistically significant association between the original ICH score and systolic- ( $p$ for trend $=0.056)$ and diastolic blood pressure ( $p$ for trend $=0.212$ ) at age $11-12$ years (Supplementary Table 4). The original ICH score was inversely associated with overweight $(\mathrm{OR}[95 \% \mathrm{CI}]: 0.52$ $[0.37-0.74, p<0.001)$ but no longer significant when excluding children with overweight (OR [95\%CI]: 0.84 [0.52-1.36], $p=0.47$ ).

\section{Discussion}

In this study, we applied an extended ICH score to a large cohort of children aged 5-6 years and investigated to what extent this score was related to cardiometabolic health at age 11-12 years. The results were compared to the original ICH score. To our knowledge this was the first time that additional components were added to the original ICH score to examine if this would improve the prediction of cardiometabolic health in children.

We found that ICH score at age 5-6 was not significantly associated with CIMT at age 11-12 according to both the extended and original ICH definition. Therefore, regarding this primary outcome, the additional criteria did not improve the prediction of CIMT, a surrogate marker for cardiovascular disease. However, both definitions showed associations of ICH score at age 5-6 with total cholesterol and BMI at age 11-12, while 
Table 1 Characteristics per ICH subgroup according to the extended ICH definition

\begin{tabular}{|c|c|c|c|c|c|}
\hline & All & Poor $(1-5)$ & Intermediate (6-7) & Good (8-9) & $P$-value ${ }^{*}$ \\
\hline N & 1666 & 188 & 934 & 544 & \\
\hline Age at first measurement (years), mean (SD) & $5.7(0.43)$ & $5.7(0.44)$ & $5.7(0.44)$ & $5.6(0.42)$ & 0.055 \\
\hline Male gender, n (\%) & $846(50.8)$ & $101(53.7)$ & $471(50.4)$ & $274(50.4)$ & 0.692 \\
\hline Ethnicity & & & & & $<0.001$ \\
\hline Dutch, n (\%) & $1210(72.7)$ & $88(47.1)$ & $677(72.5)$ & $445(81.8)$ & \\
\hline Turkey, n (\%) & $26(1.6)$ & $13(7.0)$ & $11(1.2)$ & $2(0.4)$ & \\
\hline Moroccan, n (\%) & $59(3.5)$ & $16(8.6)$ & $39(4.2)$ & $4(0.7)$ & \\
\hline Surinamese, n (\%) & $64(3.8)$ & $20(10.7)$ & $40(4.3)$ & $4(0.7)$ & \\
\hline Other western, $\mathrm{n}(\%)$ & $205(12.3)$ & $10(5.3)$ & $118(12.6)$ & $77(14.2)$ & \\
\hline Other non-Western, n (\%) & $101(6.1)$ & $40(21.4)$ & $49(5.2)$ & $12(2.2)$ & \\
\hline Maternal educational level & & & & & $<0.001$ \\
\hline Low, n (\%) & $145(8.7)$ & $57(31.0)$ & $78(8.4)$ & $10(1.8)$ & \\
\hline Middle, n (\%) & $318(19.2)$ & $56(30.4)$ & $194(20.8)$ & $68(12.5)$ & \\
\hline High, n (\%) & $1195(72.1)$ & $71(38.6)$ & $659(70.8)$ & $465(85.6)$ & \\
\hline Parent weight status & & & & & $<0.001$ \\
\hline Normal weight, n (\%) & $792(48.5)$ & $60(33.0)$ & $434(47.6)$ & $298(55.3)$ & \\
\hline One overweight parent, n (\%) & $622(38.1)$ & $75(41.2)$ & $361(39.6)$ & $186(34.5)$ & \\
\hline Two overweight parents, n (\%) & $218(13.4)$ & $47(25.8)$ & $116(12.7)$ & $55(10.2)$ & \\
\hline Family history of CVD & & & & & $<0.001$ \\
\hline None, n (\%) & $829(49.8)$ & $68(36.2)$ & $470(50.3)$ & $291(53.5)$ & \\
\hline One parent, n (\%) & $590(35.4)$ & $79(42.0)$ & $322(34.5)$ & $189(34.7)$ & \\
\hline Two parents, n (\%) & $247(14.8)$ & $41(21.8)$ & $142(15.2)$ & $64(11.8)$ & \\
\hline
\end{tabular}

Abbreviations: ICH ideal cardiovascular health, n,number, $S D$ standard deviation, $C V D$ cardiovascular diseases. ${ }^{*}$ Adjusted for age and sex

associations with systolic- and diastolic blood pressure were only found when using the extended definition. Both ICH-scores predicted subsequent overweight. When restricted to normal weight children at age 5-6 only, the extended ICH score still predicted overweight at age 11-12 whereas this association was no longer significant according to the original definition. In summary, the extended ICH improved prediction of some cardiovascular outcomes, but not our primary outcome.

\section{Interpretation of findings}

\section{Stage 1}

Ideal health factors were more common than ideal health behaviours, but most children aged 5-6 years still scored ideal on healthy weight status (87.6\%), sleeping hours $(81.4 \%)$ and screen time $(80.4 \%)$. Extra attention is needed for a healthy diet, since only $2 \%$ of the children met the healthy diet criteria. In line with our expectations, health factors were more often ideal than health behaviours as ideal behaviours precede changes in health factors. Other studies on ICH in child populations have shown similar findings [9-12].

.The low prevalence of a healthy diet is in line with other studies on ICH [10-12]. Another Dutch longitudinal study on the health of 8 year old Rotterdam born children found no children meeting Dutch dietary guidelines regarding intake of vegetables and sugar sweetened beverages [38]. As the Dutch dietary cut-offs were fairly similar to the AHA diet guideline [39], a similar percentage of ideal diet according to the AHA diet guideline can be expected. Dietary intake of both the Amsterdam and Rotterdam born children can thus be accounted as suboptimal.

In our study, the second most important ICH component was total cholesterol. We found $30.3 \%$ of 5-6 year old children with high total cholesterol concentrations. As lipoprotein concentrations change with growth and maturation (during puberty total cholesterol declines by $10-15 \%)$, it is questionable if the setpoint of cholesterol measurement at the age of 5-6 is representative for cardiovascular health $[3,40]$. Though in studies of children $>12$ years of age, the prevalence of high total cholesterol was 21.5 to $66.8 \%[9,11,12]$, which indicate that our findings are similar to findings of studies that examine older children. Next, of the 559 children included in stage 2 of this study, $31.7 \%$ had high total cholesterol concentrations at age 5-6, which declined to $26.8 \%$ at age $11-12$. 
Table 2 Association between extended ICH score and cardiovascular health outcomes at age 5-6years

\begin{tabular}{|c|c|c|c|c|c|c|c|c|c|c|}
\hline & \multirow[b]{2}{*}{ All } & \multicolumn{8}{|c|}{ Ideal Cardiovascular Health Score ${ }^{a}$} & \multirow[b]{2}{*}{$\begin{array}{l}P \text { for } \\
\text { trend }\end{array}$} \\
\hline & & 2 & 3 & 4 & 5 & 6 & 7 & 8 & 9 & \\
\hline$N, \%$ & 1666 & $2(0.1)$ & $15(0.9)$ & $35(2.1)$ & $136(8.2)$ & $\begin{array}{l}355 \\
(21.3)\end{array}$ & $\begin{array}{l}579 \\
(34.8)\end{array}$ & $527(31.6)$ & $17(1.0)$ & \\
\hline $\begin{array}{l}\text { Age at first measurement (years), } \\
\text { mean (SD) }\end{array}$ & $5.7(0.4)$ & $5.5(0.2)$ & $5.8(0.5)$ & $5.8(0.4)$ & $5.7(0.4)$ & $5.6(0.4)$ & $5.6(0.4)$ & $5.6(0.4)$ & $5.7(0.5)$ & 0.360 \\
\hline Male gender, n (\%) & $846(50.8)$ & $0(0.0)$ & $3(20.0)$ & $21(60.0)$ & 77 (56.6) & $\begin{array}{l}188 \\
(53.0)\end{array}$ & $\begin{array}{l}283 \\
(48.9)\end{array}$ & $263(49.9)$ & $11(64.7)$ & 0.055 \\
\hline \multicolumn{11}{|l|}{ Ideal health factors at age $5 / 6$ years } \\
\hline Glucose (mmol/L), mean (SE) & $4.6(0.0)$ & $4.6(0.3)$ & $4.8(0.1)$ & $4.9(0.1)$ & $4.7(0.0)$ & $4.6(0.0)$ & $4.6(0.0)$ & $4.5(0.0)$ & $4.4(0.1)$ & $<0.001$ \\
\hline $\begin{array}{l}\text { Total cholesterol (mmol/L), mean } \\
\text { (SE) }\end{array}$ & $4.0(0.0)$ & $5.4(0.4)$ & $4.4(0.2)$ & $4.3(0.1)$ & $4.2(0.1)$ & $4.3(0.0)$ & $4.1(0.0)$ & $3.7(0.0)$ & $3.6(0.2)$ & $<0.001$ \\
\hline Systolic BP (mmHg) mean (SE) & $97.2(0.2)$ & $\begin{array}{l}98.4 \\
(5.5)\end{array}$ & $\begin{array}{l}105.7 \\
(2.0)\end{array}$ & $\begin{array}{l}103.7 \\
(1.3)\end{array}$ & $\begin{array}{l}101.1 \\
(0.7)\end{array}$ & $98.4(0.4)$ & $96.8(0.3)$ & $95.3(0.3)$ & $92.7(1.9)$ & $<0.001$ \\
\hline Diastolic BP (mmHg), mean (SE) & $57.4(0.2)$ & $\begin{array}{l}64.3 \\
(5.0)\end{array}$ & $66.2(1.8)$ & $64.2(1.2)$ & $60.0(0.6)$ & $58.5(0.4)$ & $57.1(0.3)$ & $55.5(0.3)$ & $56.6(1.7)$ & $<0.001$ \\
\hline $\mathrm{HDL}-\mathrm{C}(\mathrm{mmol} / \mathrm{L})$, mean (SE) & $1.3(0.0)$ & $1.4(0.2)$ & $1.4(0.1)$ & $1.4(0.0)$ & $1.3(0.0)$ & $1.3(0.0)$ & $1.3(0.0)$ & $1.2(0.0)$ & $1.3(0.1)$ & $<0.001$ \\
\hline Triglycerides (mmol/L), mean (SE) & $0.6(0.0)$ & $0.8(0.2)$ & $0.7(0.1)$ & $0.8(0.0)$ & $0.7(0.0)$ & $0.6(0.0)$ & $0.6(0.0)$ & $0.6(0.0)$ & $0.6(0.0)$ & $<0.001$ \\
\hline \multicolumn{11}{|l|}{ Ideal health behaviors $5 / 6 y$} \\
\hline BMI, mean (SE) & $15.4(0.0)$ & $\begin{array}{l}18.9 \\
(0.9)\end{array}$ & $17.9(0.3)$ & $17.3(0.2)$ & $16.1(0.1)$ & $15.6(0.1)$ & $15.3(0.1)$ & $15.1(0.1)$ & $15.3(0.3)$ & $<0.001$ \\
\hline Ideal smoking status, n (\%) & $\begin{array}{l}1537 \\
(92.3)\end{array}$ & $0(0.0)$ & $8(53.3)$ & $23(65.7)$ & $107(78.7)$ & $\begin{array}{l}304 \\
(85.6)\end{array}$ & $\begin{array}{l}554 \\
(95.7)\end{array}$ & $524(99.4)$ & $\begin{array}{l}17 \\
(100.0)\end{array}$ & $<0.001$ \\
\hline Ideal healthy diet score, n (\%) & $33(2.0)$ & $0(0.0)$ & $0(0.0)$ & $0(0.0)$ & $0(0.0)$ & $0(0.0)$ & $3(0.5)$ & $13(2.5)$ & $\begin{array}{l}17 \\
(100.0)\end{array}$ & $<0.001$ \\
\hline Ideal physical activity, n (\%) & $\begin{array}{l}1469 \\
(88.2)\end{array}$ & $1(50.0)$ & $7(46.7)$ & $21(60.0)$ & $90(66.2)$ & $\begin{array}{l}286 \\
(80.6)\end{array}$ & $\begin{array}{l}521 \\
(90.0)\end{array}$ & $526(99.8)$ & $\begin{array}{l}17 \\
(100.0)\end{array}$ & $<0.001$ \\
\hline Ideal screen time, n (\%) & $\begin{array}{l}1339 \\
(80.4)\end{array}$ & $0(0.0)$ & $4(26.7)$ & $8(22.9)$ & $49(36.0)$ & $\begin{array}{l}228 \\
(64.2)\end{array}$ & $\begin{array}{l}506 \\
(87.4)\end{array}$ & $\begin{array}{l}527 \\
(100.0)\end{array}$ & $\begin{array}{l}17 \\
(100.0)\end{array}$ & $<0.001$ \\
\hline Ideal sleep behavior, n (\%) & $\begin{array}{l}1356 \\
(81.4)\end{array}$ & $0(0.0)$ & $2(13.3)$ & $14(40.0)$ & $60(44.1)$ & $\begin{array}{l}244 \\
(68.7)\end{array}$ & $\begin{array}{l}493 \\
(85.1)\end{array}$ & $526(99.8)$ & $\begin{array}{l}17 \\
(100.0)\end{array}$ & $<0.001$ \\
\hline
\end{tabular}

Abbreviations: $I C H$ ideal cardiovascular health, $N$ number, $S D$ standard deviation, $S E$ standard error, $B M I$ body mass index, $B P$ blood pressure, $H D L-C$ high-density lipoprotein cholesterol. Results are adjusted for age and sex

${ }^{a}$ There were no children with 0 or $1 \mathrm{ICH}$ point

\section{Stage 2}

Ideal cardiovascular health in childhood has shown to be associated with CIMT measurements in adulthood [9]. Nevertheless, clustering of CVD risk factors starts in childhood and vascular changes may therefore also occur at younger ages. In our sample ICH score at age 5-6 was not related to CIMT measurements at followup 6 years later. The variation of CIMT in this group was small, which can be explained by the fact that we examined a relative young and healthy population of the same age. According to the systematic review of van den Munckhof et al. [41] on CIMT in an apparently healthy adult population, $84 \%$ of CIMT can be explained by age. In contrast, several other studies in children found associations of ICH components and CIMT in childhood $[14,15,37,42]$. The children included in these studies were mainly older at baseline (range 8 to 11) than our sample and CIMT was also measured at older ages (range 15 to 21) [14, 15, 37] However, the study by Geerts et al. [42] found an association between prenatal exposure to smoking and CIMT measurements at the age of 5 years old. The inconsistency of findings may be explained by the way in which CIMT was measured; in our study a hand guided ultrasound was used, which has a lower sensitivity than automatic devices. In addition, we performed measurements at three different angles in one segment (common carotid artery), while other studies performed measurements at one angle in three different segments (common carotid artery, internal carotid artery, carotid bulb). Lastly, different sonographers can have different findings and all studies used different readers. This inevitably makes results difficult to compare between studies.

The extended ICH definition at age 5-6 has stronger associations with systolic- and diastolic blood pressure and BMI at age 11-12 than the original definition and 
Table 3 Association between extended ICH score at age 5-6years and cardiovascular health outcomes at age 11-12 years

\begin{tabular}{|c|c|c|c|c|c|c|c|c|c|c|}
\hline & \multicolumn{10}{|c|}{ Ideal Cardiovascular Health Score ${ }^{a}$} \\
\hline & All & 2 & 3 & 4 & 5 & 6 & 7 & 8 & 9 & $\begin{array}{l}P \text { for } \\
\text { trend }\end{array}$ \\
\hline N, \% & 559 & $2(0.4)$ & $4(0.7)$ & $6(1.1)$ & $38(6.8)$ & $119(21.3)$ & $198(35.4)$ & $187(33.5)$ & $5(0.9)$ & \\
\hline $\begin{array}{l}\text { Age at first measurement } \\
\text { (years), mean (SD) }\end{array}$ & $5.7(0.4)$ & $5.5(0.2)$ & $5.7(0.4)$ & $5.7(0.5)$ & $5.8(0.5)$ & $5.7(0.4)$ & $5.7(0.5)$ & $5.7(0.4)$ & $5.6(0.5)$ & 0.943 \\
\hline $\begin{array}{l}\text { Age at follow up (years), } \\
\text { mean (SD) }\end{array}$ & $11.8(0.4)$ & $12.1(0.3)$ & $11.4(0.2)$ & $12.0(0.4)$ & $11.9(0.3)$ & $11.7(0.4)$ & $11.8(0.4)$ & $11.8(0.3)$ & $11.5(0.3)$ & 0.011 \\
\hline Maturation, mean (SD) & $1.5(0.5)$ & $1.5(0.1)$ & $2.1(1.1)$ & $1.7(0.8)$ & $1.6(0.5)$ & $1.5(0.6)$ & $1.5(0.6)$ & $1.4(0.4)$ & $1.3(0.5)$ & 0.107 \\
\hline \multicolumn{11}{|l|}{ Cardiovascular health $11 / 12 y$} \\
\hline Glucose (mmol/L), mean (SE) & $4.9(0.0)$ & $4.5(0.4)$ & $4.6(0.3)$ & $4.8(0.2)$ & $5.2(0.1)$ & $4.9(0.1)$ & $4.9(0.0)$ & $4.9(0.0)$ & $4.6(0.3)$ & 0.920 \\
\hline $\begin{array}{l}\text { Total cholesterol (mmol/L), } \\
\text { mean (SE) }\end{array}$ & $4.1(0.0)$ & $5.0(0.4)$ & $4.5(0.3)$ & $4.1(0.3)$ & $4.1(0.1)$ & $4.3(0.1)$ & $4.1(0.0)$ & $3.9(0.0)$ & $3.5(0.3)$ & $<0.001$ \\
\hline $\begin{array}{l}\text { Systolic BP (mmHg), mean } \\
\text { (SE) }\end{array}$ & $105.2(0.4)$ & $110.8(5.8)$ & $110.6(4.1)$ & $113.0(3.7)$ & $106.8(1.4)$ & $105.2(0.8)$ & $105.1(0.6)$ & $104.2(0.6)$ & $109.3(3.7)$ & 0.012 \\
\hline $\begin{array}{l}\text { Diastolic BP (mmHg), } \\
\text { mean (SE) }\end{array}$ & $60.1(0.3)$ & $64.4(4.6)$ & $63.2(3.2)$ & $68.9(2.9)$ & $60.6(1.1)$ & $60.5(0.6)$ & $60.1(0.5)$ & $59.1(0.5)$ & $66.5(2.9)$ & 0.011 \\
\hline HDL-C (mmol/L), mean (SE) & $1.5(0.0)$ & $1.4(0.2)$ & $1.5(0.2)$ & $1.4(0.1)$ & $1.5(0.1)$ & $1.5(0.0)$ & $1.5(0.0)$ & $1.5(0.0)$ & $1.0(0.2)$ & 0.309 \\
\hline $\begin{array}{l}\text { Triglyceriden }(\mathrm{mmol} / \mathrm{L}) \text {, } \\
\text { mean (SE) }\end{array}$ & $1.0(0.0)$ & $1.0(0.4)$ & $0.8(0.3)$ & $1.2(0.2)$ & $1.1(0.1)$ & $1.0(0.1)$ & $0.9(0.0)$ & $1.0(0.0)$ & $0.5(0.4)$ & 0.468 \\
\hline BMI, mean (SE) & $17.6(0.1)$ & $20.3(1.6)$ & $20.2(1.1)$ & $22.1(1.0)$ & $18.2(0.4)$ & $18.4(0.2)$ & $17.2(0.2)$ & $17.2(0.2)$ & $17.1(1.0)$ & $<0.001$ \\
\hline CIMT (mm), mean (SE) & $\begin{array}{l}0.462 \\
(0.001)\end{array}$ & $\begin{array}{l}0.445 \\
(0.020)\end{array}$ & $\begin{array}{l}0.485 \\
(0.015)\end{array}$ & $\begin{array}{l}0.429 \\
(0.020)\end{array}$ & $\begin{array}{l}0.455 \\
(0.006)\end{array}$ & $\begin{array}{l}0.458 \\
(0.003)\end{array}$ & $\begin{array}{l}0.462 \\
(0.002)\end{array}$ & $\begin{array}{l}0.464 \\
(0.002)\end{array}$ & $\begin{array}{l}0.457 \\
(0.013)\end{array}$ & 0.123 \\
\hline
\end{tabular}

Abbreviations: $N$ number, $S D$ standard deviation, $S E$ standard error, $B P$ blood pressure, $H D L-C$ high-density lipoprotein cholesterol, BMI body mass index, CIMT carotid intima-media thickness

Results are adjusted for age, sex and maturation. ${ }^{\mathrm{a}}$ There were no children with 0 or $1 \mathrm{ICH}$ point.

remained when testing only in non-overweight individuals aged $5-6$ years. This difference cannot be explained by only one of the three additional components used in the extended definition. The difference is thus due to the clustering of additional components. This might be because of the bi-directional relationship between sleep duration and physical activity and sedentary behavior [43]. The implication for our study is that children with ideal levels of one of the three behaviours (sleep duration, physical activity or screen time) were more likely

Table 4 Odds ratios and 95\% confidence intervals for the association between ICH score (extended and original) at age 5-6 years and cardiometabolic outcomes at age 11-12 years

\begin{tabular}{llllllll}
\hline & \multicolumn{3}{c}{ Extended definition } & & \multicolumn{3}{c}{ Original definition } \\
\cline { 2 - 3 } & $\mathbf{O R}^{\mathbf{a}}$ & $\mathbf{9 5 \%} \mathbf{C l}$ & $\mathbf{P}$ & & $\mathbf{O R}^{\mathbf{a}}$ & $\mathbf{9 5 \%} \mathbf{C l}$ & $\mathbf{P}$ \\
\hline (Pre)Hypertension & 0.85 & $0.66-1.09$ & 0.203 & & 0.89 & $0.62-1.28$ & 0.526 \\
Metabolic Syndrome & 0.81 & $0.66-1.01$ & 0.056 & & 0.89 & $0.64-1.22$ & 0.456 \\
Low HDL-C & 1.05 & $0.78-1.41$ & 0.757 & & 1.30 & $0.84-2.02$ & 0.232 \\
High triglycerides & 1.00 & $0.82-1.23$ & 0.940 & & 1.02 & $0.77-1.36$ & 0.879 \\
Overweight & 0.54 & $0.43-0.68$ & $<0.001$ & & 0.52 & $0.37-0.74$ & $<0.001$ \\
Increased risk CIMT & 1.04 & $0.77-1.40$ & 0.802 & & 1.01 & $0.67-1.53$ & 0.956 \\
\hline
\end{tabular}

Abbreviations: HDL-C high-density lipoprotein cholesterol, CIMT carotid intimamedia thickness, $\mathrm{OR}$ odds ratio, $\mathrm{Cl}$ confidence interval

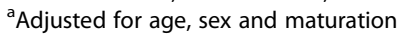

to have ideal levels of the other cardiovascular components, which resulted in a considerably higher ICH-level. As sleep duration, physical activity and screen time are linked, the extended definition gives a larger variance between ICH levels of those with and without ideal physical activity compared to the original ICH definition. Since there is a larger variation in ICH-level, associations of ICH-level with cardiometabolic outcomes are more likely. Furthermore, as unhealthy behaviour leads to changes in blood cholesterol concentrations which in turn leads to increased CIMT, it could be that adding more behaviours to the $\mathrm{ICH}$ construct will make the ICH construct more sensitive for predicting cardiovascular health.

The association between cardiometabolic outcomes and the additional components, namely: screen time, sleep behaviour and prenatal smoke exposure have been examined in previous studies [20, 21, 44]. In children, associations between sedentary behaviour and blood pressure are inconsistent [20], although there is some evidence for a relationship between short sleep duration in children and increased blood pressure [21]. Prenatal smoke exposure is not associated with an increased blood pressure in childhood according to a Portuguese study in $3-10$ year old children $(n \approx 2500)$. However prenatal smoke exposure is associated with an increase in 
BMI ( $n=17,286)$ [44]. Sleep duration in childhood is also found to be inversely associated with BMI [21], while the evidence for sedentary behaviour is inconsistent [20]. It is possible that the addition of the extra components single-handedly led to the extra association. However, it might also be that the combination of more non-ideal health behaviours is the basis of reduced cardiometabolic health which is associated with higher levels of blood pressure and BMI.

\section{Strengths and limitations}

Our study has some important strengths, including the longitudinal study design and its large sample size. Measurements took place at the same timepoint, by the same researchers with the same measuring instruments. Further, extensive measurements were done with the validated FFQ at stage 1 in the study [24]. The present study is the first to examine $\mathrm{ICH}$ in childhood with CIMT measurement in children as young as 11-12 years old.

The present study also has several limitations. First, our sample differed from the ABCD-cohort in terms of ethnicity, maternal educational level and family history of CVD. As Supplementary Table 1 shows, precisely those participants are more likely to have a poor cardiovascular health. Therefore, our results probably overestimate the prevalence of ideal cardiovascular health in the ABCD-cohort. Not all children participating at age 5-6 also participated 5-6 years later, though the study cohort still consisted of 559 individuals. Information on health behaviours were reported by parents and thus all subjective. It is conceivable that parents perceive or present their child's behaviour in a more positive manner than the actual situation is. This could lead to an overestimation of healthy behaviour, resulting in a reduction of the observed association of behaviour and disease, making it less likely that there is a significant statistical outcome [45]. Health factors were measured during the health check and automatic oscillometric devices were used for blood pressure measurements, while the blood pressure table of the American Academy of Paediatrics was made by auscultatory measurements [35]. Compared to blood pressure values measured by the auscultatory method, the oscillometric blood pressure device used in the present study found on average (SD) 4.6 (4.9) $\mathrm{mmHg}$ higher systolic blood pressure values and 3.3 (5.4) $\mathrm{mmHg}$ lower diastolic blood pressure values [32]. This could have led to an overestimation of (pre-)hypertension because of higher levels of systolic blood pressure. However, a systematically overestimation of blood pressure values would not affect the present study. Many paediatric studies now use automatic devices in combination with the standard blood pressure Tables [46], thus findings of this study are comparable with other available research. For outcome measures, our study was limited to CIMT measurement and CVD risk factors since cardiovascular events could not be studied as clinical outcome at this age.

\section{Implications}

Our study implicates that to raise a healthy generation, there is need for dietary interventions in Dutch children. Adherence to the healthy diet guidelines among the children was extremely low, which is unfortunately since dietary habits have shown to track into adulthood [47].

As the extended definition did not improve the prediction of CIMT and most cardiometabolic factors, we do not recommend the AHA to add the extra components to their definition yet. First there is need for further research.

In compliance with other studies [48, 49], our study shows that children with a non-western ethnicity and lower educated mothers were more likely to have a poorer cardiovascular health, public health interventions regarding cardiovascular health should focus particularly on these at risk individuals.

\section{Recommendations for future research}

Further research is needed to gain insight into the associations between lifestyle of young children and cardiovascular health later in life. We recommend other researchers to look at $\mathrm{ICH}$ in children under 12 years in relation to cardiometabolic outcomes at a later age and explore the addition of sleep duration, screen time and prenatal smoke exposure to ICH on these outcomes. We also encourage other researchers to examine subpopulations (i.e. overweight children). Making use of objective measures for health behaviours would be recommended.

The ABCD-cohort will also be followed up longer and report on associations of $\mathrm{ICH}$ at age 5-6 and cardiometabolic health at an older age.

\section{Conclusion}

This study showed that $33 \%$ of children meet the criteria for an ideal cardiovascular health. A healthy diet was least prevalent among 5-year olds (2\%). Extending the ICH score in young children with additional health behaviours improved the prediction of some cardiometabolic outcomes, but not CIMT in preadolescence, compared to the original $\mathrm{ICH}$ score.

\section{Supplementary Information}

The online version contains supplementary material available at https://doi. org/10.1186/s12966-021-01090-2.

Additional file 1: Supplementary Table 1. Characteristics of included and non-included children. Supplementary Table 2. Defining Ideal Cardiovascular Health. Supplementary Table 3. Association between 
original ICH score and cardiovascular health outcomes at age 5-6 years. Supplementary Table 4. Association between original ICH score at age 5-6 years and cardiovascular health outcomes at age 11-12 years.

\section{Acknowledgements}

The authors thank all participating hospitals, obstetric clinics, general practitioners, Youth Health Care Centres and primary schools for their contribution to data collection for the ABCD study; we thank all the participating women and children for their valuable cooperation.

\section{Authors' contributions}

All the authors have participated in the study to a significant extent and have met the criteria for authorship as established by the International Committee of Medical Journal Editors. The author(s) read and approved the final manuscript.

\section{Funding}

This part of the ABCD-study was financially supported by the Netherlands Organisation for Health Research and Development (Grants 21000076, 92003489, 40-00812-98-11010), Dutch Heart Foundation (grant 2007B103) and Sarphati Amsterdam. The funders had no role in preparing and conducting this manuscript, in interpreting and deciding to publish the results, or in drafting this manuscript. Open Access funding enabled by Amsterdam UMC.

\section{Availability of data and materials}

The individual data are not available for a public repository for ethical reasons but can be made available to other researchers for purposes of reproducing results or for collaboration. Researchers wishing to apply for the data can contact the project leader of the ABCD-study (abcd@amsterdamumc.nl).

\section{Ethics approval and consent to participate}

Approval for the ABCD study was obtained from the Central Committee on Research involving Human Subjects in the Netherlands, the Medical Ethical Committees of the participating hospitals, and from the Registration Committee of the Municipality of Amsterdam. Written informed consent was obtained from all participating mothers.

The Ethics approval numbers for the different parts of the ABCD-study are:

- Pregnancy questionnaire: METC AMC 02/039\#02.17.392

- Questionnaires and health check at age 5-6: METC AMC 02/ 039\#07.17.1039

- Questionnaires and health check at age 11-12: METC AMC 2015_154\#B2015655a

\section{Consent for publication}

Not applicable.

\section{Competing interests}

Authors declare no competing interests.

\section{Author details}

${ }^{1}$ Department of Public and Occupational Health, Amsterdam Public Health Research Institute, Amsterdam UMC, University of Amsterdam, PO Box 22700, Meibergdreef 9, room J2-209, 1100 DE Amsterdam, The Netherlands. ${ }^{2}$ Department of Sports Science and Physical Education, University of Agder, PO BOX 422, 4604 Kristiansand, Norway. ${ }^{3}$ Department of Clinical Epidemiology, Biostatistics and Bioinformatics, Amsterdam Cardiovascular Sciences Research Institute, Amsterdam Public Health Research Institute, Amsterdam UMC, University of Amsterdam, PO Box 22700, Meibergdreef 9, room J1B-209-1, 1100 DE Amsterdam, The Netherlands. ${ }^{4}$ Department of Public and Occupational Health, Amsterdam Public Health Research Institute, Amsterdam UMC, Vrije Universiteit, PO Box 7057, van der Boechorststraat 7. 1081 BT, Amsterdam, The Netherlands.
Received: 28 August 2020 Accepted: 19 January 2021

Published online: 06 March 2021

\section{References}

1. McAloon CJ, Boylan LM, Hamborg T, Stallard N, Osman F, Lim PB, et al. The changing face of cardiovascular disease 2000-2012: An analysis of the world health organisation global health estimates data. Int J Cardiol. 2016;224: 256-264. Available from: http://www.ncbi.nlm.nih.gov/pubmed/27664572 [cited 2018 Feb 26].

2. Erald G, Erenson SB, Athanur S, Rinivasan RS, Eihang W, Ao B, et al. Association between multiple cardiovascular risk factors and atherosclerosis in children and young adults. N Engl J Med. 1998;338(23):1650-1656. Available from: http://www.nejm.org.ezproxy.library.wur.nl/doi/pdf/10.1056/ NEJM199806043382302 [cited 2018 Feb 26]

3. Steinberger J, Daniels SR, Hagberg N, Isasi C, Kelly AS, Lloyd-Jones D, et al. Cardiovascular Health Promotion in Children: Challenges and Opportunities for 2020 and Beyond: A Scientific Statement From the American Heart Association. Circulation. 2016134 (12):236-255. Available from: https://wwwncbi-nlm-nih-gov.ezproxy.library.wur.nl/pmc/articles/PMC5218582/pdf/ nihms838989.pdf [cited 2018 Feb 27].

4. Lloyd-Jones DM, Hong Y, Labarthe D, Mozaffarian D, Appel L, Van Horn L, et al. Defining and setting national goals for cardiovascular health promotion and disease reduction: The american heart association's strategic impact goal through 2020 and beyond. Circulation. 2010;121(4):586-613.

5. Aneni EC, Crippa A, Osondu CU, Valero-Elizondo J, Younus A, Nasir K, et al. Estimates of mortality benefit from ideal cardiovascular health metrics: A dose response meta-analysis. J Am Heart Assoc. 2017;6(12).

6. Maclagan LC, Tu JV. Using the concept of ideal cardiovascular health to measure population health: a review. Curr Opin Cardiol. 2015;30(5):518-24.

7. Guo L, Zhang S. Association between ideal cardiovascular health metrics and risk of cardiovascular events or mortality: A meta-analysis of prospective studies. Clin Cardiol. 2017:1339-46.

8. Younus A, Aneni EC, Spatz ES, Osondu CU, Roberson L, Ogunmoroti O, et al. A systematic review of the prevalence and outcomes of ideal cardiovascular health in US and non-US populations. Mayo Clin Proc. 2016;91(5):649-70. https://doi.org/10.1016/j.mayocp.2016.01.019.

9. Laitinen T, Laitinen TT, Pahkala K, Magnussen CG, Viikari JSA, Oikonen M, et al. Ideal cardiovascular health in childhood and cardiometabolic outcomes in adulthood: The cardiovascular risk in young finns study. Circulation. 2012;125(16):1971-8.

10. Dong H, Yan Y, Liu J, Zhao X, Cheng H, Hou D, et al. Alarming trends in ideal cardiovascular health among children and adolescents in Beijing, China, 2004 to 2014. Int J Cardiol. 2017;231(2017):264-70. https://doi.org/10. 1016/j.jijcard.2016.12.027.

11. Yang Q, Yuan K, Gregg EW, Loustalot F, Fang J, Hong Y, et al. Trends and Clustering of Cardiovascular Health Metrics Among U.S. Adolescents 19882010. 2014; Available from: https://www.jahonline.org/article/S1054-139X(14 00159-1/pdf [cited 2018 Jun 29]

12. González-Gil EM, Santabárbara J, Ruiz JR, Bel-Serrat S, Huybrechts I, PedreroChamizo $R$, et al. Ideal cardiovascular health and inflammation in European adolescents: The HELENA study. Nutr Metab Cardiovasc Dis. 2017;27(5):44755.

13. Hanvey AN, Mensah FK, Clifford SA, Wake M. Adolescent Cardiovascular Functional and Structural Outcomes of Growth Trajectories from Infancy: Prospective Community-Based Study. Child Obes. 2017;13(2):154-163. Available from: http://online.liebertpub.com/doi/10.1089/chi.2016.0263 [cited 2018 Mar 27]

14. Menezes AMB, da Silva CTB, Wehrmeister FC, Oliveira PD, Oliveira IO, Gonçalves $\mathrm{H}$, et al. Adiposity during adolescence and carotid intima-media thickness in adulthood: Results from the 1993 Pelotas Birth Cohort. Atherosclerosis. 2016;255:25-30. Available from: http://www.ncbi.nlm.nih. gov/pubmed/27816805 [cited 2018 Mar 26].

15. Yajnik CS, Katre PA, Joshi SM, Kumaran K, Bhat DS, Lubree HG, et al. Higher glucose, insulin and insulin resistance (HOMA-IR) in childhood predict adverse cardiovascular risk in early adulthood: the Pune Children's Study. Diabetologia. 2015;58(7):1626-1636. Available from: http://link.springer. com/10.1007/s00125-015-3602-z [cited 2018 Mar 26]

16. Geerts CC, Bots ML, Grobbee DE, Uiterwaal CSPM. Parental smoking and vascular damage in young adult offspring: is early life exposure critical? The atherosclerosis risk in young adults study. Arterioscler Thromb Vasc Biol. 
2008;28(12):2296-2302. Available from: http://www.ncbi.nlm.nih.gov/ pubmed/19020316 [cited 2018 Mar 27].

17. Ayer JG, Belousova E, Harmer JA, David C, Marks GB, Celermajer DS. Maternal cigarette smoking is associated with reduced high-density lipoprotein cholesterol in healthy 8-year-old children. Eur Heart J. 2011; 32(19):2446-2453. Available from: https://academic.oup.com/eurhearti/ article-lookup/doi/10.1093/eurheartj/ehr174 [cited 2018 Mar 26]

18. Ried-Larsen M, Grontveld A, Moller NC, Larsen KT, Froberg K, Andersen L. Association between objectively measured physical activity intensity in childhood and measures of subclinical cardiovascular disease in adolescence: prospective observations from the European Heart Study. Br J Sports Med. 2014;48:1502-7 Available from: http://ovidsp.ovid.com/athens/ ovidweb.cgi? T=JS\&NEWS=N\&PAGE=fulltext\&AN=3676641\&D=med2.

19. Covassin N, Singh P. Sleep Duration and Cardiovascular Disease Risk: Epidemiologic and Experimental Evidence. Sleep Med Clin. 2016;11:81-89. Available from: https://www-ncbi-nlm-nih-gov.ezproxy.library.wur.nl/pmc/ articles/PMC4791534/pdf/nihms735846.pdf [cited 2018 Jun 25]

20. Chinapaw MJM, Proper KI, Brug J, Van Mechelen W, Singh AS. Relationship between young peoples' sedentary behaviour and biomedical health indicators: a systematic review of prospective studieso br_865 621.632 . Obes Rev. 2011;12:621-32.

21. Matthews KA, Pantesco EJM. Sleep Characteristics and Cardiovascular Risk in Children and Adolescents: An Enumerative Review. Sleep Med. 2016;18:3649. Available from: https://www-ncbi-nlm-nih-gov.ezproxy.library.wur.nl/ pmc/articles/PMC4689674/pdf/nihms705296.pdf [cited 2018 Jun 15]

22. Mancini GBJ, Dahlöf B, Díez J, Cohn JN. Surrogate markers for cardiovascular disease: Structural markers. Circulation. 2004;109 Available from: http://www. circulationaha.org [cited 2020 Nov 19]. Lippincott Williams \& Wilkins.

23. Van Eijsden M, Vrijkotte TGM, Gemke RJBJ, Van der Wal MF. Cohort profile: The Amsterdam born children and their development (ABCD) study. Int J Epidemiol. 2011;40(5):1176-86.

24. Dutman AE, Stafleu A, Kruizinga A, Brants HA, Westerterp KR, Kistemaker $C$, et al. Validation of an FFQ and options for data processing using the doubly labelled water method in children. Public Health Nutr. 2010; 14(3):410-417. Available from: https://www.cambridge.org/core/services/ aop-cambridge-core/content/view/F4491D1DC9C312E46A73F3F795 97CABF/S1368980010002119a.pdf/validation_of_an_ffq_and_options_for_ data_processing_using_the_doubly_labelled_water_method_in_children. pdf [cited 2018 Mar 23]

25. Silberberg JS, Wlodarczyk J, Fryer J, Robertson R, Hensley MJ. Risk Associated with Various Definitions of Family History of Coronary Heart Disease The Newcastle Family History Study II. 1998;147(12) Available from: https:// academic.oup.com/aje/article-abstract/147/12/1133/93184.

26. Petersen AC, Crockett L, Richards M, Boxer A. A self-report measure of pubertal status: reliability, validity, and initial norms. J Youth Adolesc. 1988

27. Burghard M, Knitel K, Van Oost I, Tremblay MS, Takken T. Is our youth cycling to health? Results from the Netherlands' 2016 report card on physical activity for children and youth. J Phys Act Health. 2016;13(11):S218-24.

28. Health Council of the Netherlands. Guideline for dietary fibre intake. 2006 Available from: https://www.gezondheidsraad.nl/sites/default/files/Dietary_ fibre_intake_0.pdf [cited 2018 Jun 15]

29. Chinapaw MJM, Altenburg TM, Van Eijsden M, Gemke RJBJ, Vrijkotte TGM. Screen time and cardiometabolic function in Dutch 5-6 year olds: crosssectional analysis of the ABCD-study. BMC Public Health. 2014;14(1):1-6.

30. Gootjes J, Tel RM, Bergkamp FJM, Gorgels JPMC. Laboratory evaluation of a novel capillary blood sampling device for measuring eight clinical chemistry parameters and HbA1c. Clin Chim Acta. 2009;401(1-2):152-157. Available from: https:/www-sciencedirect-com.ezproxy.library.wur.nl/science/article/pii/ S0009898108006049?_rdoc=1\&_fmt=high\&_origin=gateway\&_docanchor= \&md5=b8429449ccfc9c30159a5f9aeaa92ffb\&ccp=y [cited 2018 Jun 15]

31. Alere. Alere Cholestech LDX Lipid Profile GLU Cassettes CLSI. 2004. (CLSI196 vC 10/17). Available from: https://www.alere.com/en/home/product-details/ cholestech-Idx-system.html

32. Stergiou GS, Yiannes NG, Rarra VC. Validation of the Omron 705 IT oscillometric device for home blood pressure measurement in children and adolescents: The Arsakion school study. Blood Press Monit. 2006; 11(4):229-34.

33. van den Berg G, van Eijsden M, Galindo-Garre F, Vrijkotte TGGR. Reinoud J.B. J. Gemke. Explaining socioeconomic inequalities in childhood blood pressure and prehypertension. The ABCD study. Hypertension. 2013;61(1): 35-41.
34. WHO Multicentre Growth Reference Study Group. WHO Child growth standards based on length/height, weight and age. Acta Paediatr Suppl. 2006;450:76-85.

35. Flynn J, Kaelber D, Baker-Smith C, Blowey D, Carrol A, Daniels SR, et al. Clinical practice guideline for screening and Management of High Blood Pressure in children and adolescents. Pediatr Transplant. 2017;140(3):e20171904.

36. Hirshkowitz $M$, Whiton $K$, Albert SM, Alessi C, Bruni O, DonCarlos L, et al. National Sleep Foundation's updated sleep duration recommendations: final report. SLEH. 2015;1:233-43. https://doi.org/10.1016/j.sleh.2015.10.004 [cited 2018 May 8].

37. Juonala M, Singh GR, Davison B, Van Schilfgaarde K, Skilton MR, Sabin MA et al. Childhood metabolic syndrome, inflammation and carotid intima-

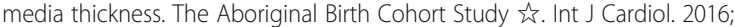
203:32-36. Available from: https://c7tuhp341954lk5agfqc6lr.amc-literatuur. amc.nl/S0167527315306379/1-s2.0-S0167527315306379-main.pdf? tid=93c2 ce4c-853c-42f4-8126-c81e9dfbe86c\&acdnat=1522060947_99390a7a2032 baeb2978c540abcele68 [cited 2018 Mar 26]

38. van der Velde LA, Nguyen AN, Schoufour JD, Geelen A, Jaddoe WWV, Franco $\mathrm{OH}$, et al. Diet quality in childhood: the generation R study. Eur J Nutr. 2018.

39. The Wheel of Five guidelines [Dutch: Richtlijnen Schijf van Vijf]. The Hague, the Netherlands; 2016. Available from: https://www.voedingscentrum.nl/ Assets/Uploads/voedingscentrum/Documents/Professionals/Schijf van Vijf/ Voedingscentrum Richtlijnen Schijf van Vijf 2016 4.pdf.

40. Balder JW, Lansberg PJ, Hof MH, Wiegman A, Hutten BA, Kuivenhoven JA. Pediatric lipid reference values in the general population: The Dutch lifelines cohort study. J Clin Lipidol. 2018;12:1208-16. https://doi.org/10. 1016/j.jacl.2018.05.011 [cited 2020 may 11].

41. Van Den Munckhof ICL, Jones H, Hopman MTE, De Graaf J, Nyakayiru Jean, Van Dijk B, et al. Relation between age and carotid artery intima-medial thickness: a systematic review : Relation between age and cIMT 2018;

42. Geerts, CC, Bots, ML, Cornelis K van der Ent, Diederick E Grobbee, Cuno S P M Uiterwaal. Parental Smoking and Vascular Damage in Their 5-year-old Children. Pediatrics. 2012;129(1):45-54. Available from: http://pediatrics. aappublications.org/content/pediatrics/129/1/45.full.pdf [cited 2018 Mar 22]

43. Lin Y, Tremblay MS, Katzmarzyk PT, Fogelholm M, Hu G, Lambert EV, et al. Temporal and bi-directional associations between sleep duration and physical activity/sedentary time in children: an international comparison. Prev Med (Baltim). 2018;2018(111):436-41.

44. Li L, Peters H, Gama A, MIM C, HGM N, Rosado-Marques V, et al. Maternal smoking in pregnancy association with childhood adiposity and blood pressure. Pediatr Obes. 2016;11:202-9.

45. Norwood MS, Hughes JP, Amico KR. The validity of self-reported behaviors: methods for estimating underreporting of risk behaviors. Ann Epidemiol. 2016;26(9):612-8 e2.

46. Parker ED, Kharbanda EO, Sinaiko AR. Are we measuring blood pressure correctly in children, particularly in obesity? Arch Dis Child. 2016;101(11): 990-991. Available from: http://www.ncbinlm.nih.gov/pubmed/27470161 [cited 2018 Jul 4].

47. Craigie AM, Lake AA, Kelly SA, Adamson AJ, Mathers JC. Tracking of obesityrelated behaviours from childhood to adulthood: a systematic review. Maturitas. 2011;2011(70):266-84.

48. Rashid V, Engberink MF, Van Eijsden M, Nicolaou M, Dekker LH, Verhoeff AP, et al. Ethnicity and socioeconomic status are related to dietary patterns at age 5 in the Amsterdam born children and their development (ABCD) cohort. BMC Public Health. 2018;18:115.

49. van Dommelen P, Schönbeck Y, Hirasing R.A, van Buuren S. Call for early prevention: prevalence rates of overweight among Turkish and Moroccan children in The Netherlands. Eur J Public Health. 2015;25(5):828-833. Available from: https://academic.oup.com/eurpub/article-abstract/25/5/82 8/2398969 [cited 2020 Jun 8]

\section{Publisher's Note}

Springer Nature remains neutral with regard to jurisdictional claims in published maps and institutional affiliations. 